\title{
Using paleoecology to understand natural ecological character in Ramsar wetlands
}

Peter A. Gell

\section{Long-term data from paleoecology can help identify the "natural ecological character" of wetlands and so inform "limits of acceptable change" and the design of appropriate restoration targets for management that consider the historical range of variability.}

While the knowledge of the biodiversity of wetlands is poor, it is understood that, while they cover a small fraction ( 6\%) of the Earth's surface, they support a disproportionately rich assemblage of plants and animals. However, freshwater ecosystems are among the most threatened in the world and are suffering biodiversity declines as great, or greater, than terrestrial systems (Dudgeon et al. 2006). Global estimates sug gest freshwater vertebrate populations have declined at $2 \%$ per annum since the 1960 s through a combination of overexploitation of water resources, pollution, hydrological change, degradation of habitat and invasive species. While these effects vary regionally, it is estimated that $30-90 \%$ of the world's wetlands have been destroyed or strongly modified (Junk et al. 2013). At an international level, the Ramsar Convention is an important framework to protect the world's remaining significant wetlands.

\section{What is Ramsar?}

The Ramsar Convention is a UN program that seeks to conserve the world's wetlands and their ecosystems. First ratified in Ramsar, Iran, in 1971, it is now represented by 169 countries which have at least one nominated site on the list. The main purpose of the Convention is to mitigate the worldwide loss and degradation of wetlands and this goal is now extended to the wise use of all wetlands within the signatory countries (www.ramsar. org). Today 2243 wetlands are protected under the Convention covering 216,320,717 ha of wetland habitat.

Listing involves the nomination of the site's boundaries and development of a case that the site satisfies one or more of nine criteria. Mostly the criteria relate to the site's role in hosting substantial populations of rare or vulnerable fish or bird species or communities. Signatory nations are required to produce a Site Information Sheet and are also encouraged to produce management plans within which they identify the "natural ecological character" of the site. Invariably this description is drawn from the character of the wetland at the time of, or through the period leading up to, listing.

All signatory nations are required to report to the Ramsar Secretariat if a wetland has changed, or is likely to change, from the identified condition. This invokes a pathway of committing to restore the site, offsetting it by nominating an equivalent site, or invoking "national economic interest". However, despite the Millennium Ecosystem Assessment reporting widespread loss and decline in the world's wetlands, few nations have reported change in site condition.

The mismatch between the observations of the declining extent and condition of the world's freshwater systems and the paucity of nation's reporting that their wetland has changed, or is likely to change in the future, could be interpreted as all declines occur outside the network of listed sites. This would confer considerable merit to the Ramsar Convention in mitigating the global decline in condition. However, what is more likely is that nations have been either unable to detect change, or have been reluctant to report because of the challenges of restoration, and how it may reflect their record of environmental management. In order to drive better reporting of the condition of a wetland relative to this baseline, the Convention has requested that nations identify the limits of acceptable change.

\section{Means of determining the limits of accept- able change have been proposed based on the historical variability in a measured condi- tion in the past (Fig. 1). However, the moni- toring of wetland condition and populations of aquatic flora and fauna has a short history, even among developed nations with a strong tradition of aquatic-system research. Also, the influence of low frequency cycles of change question the representativeness of records of variability that may even span sev- eral decades. Paleoecological approaches can, and have, extended this knowledge of variability and so play an important role in the understanding of wetland change over time.}

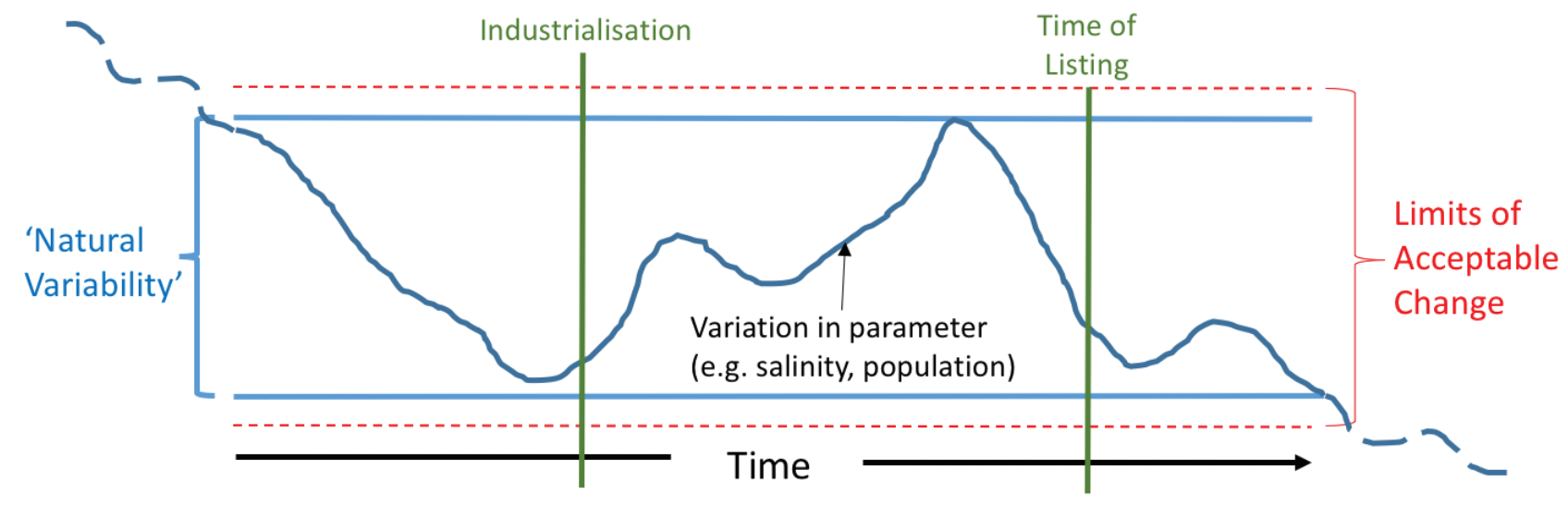

Figure 1: Theoretical approach to developing "Limits of Acceptable Change" within Ramsar wetlands (adapted from Phillips 2006). In principle, the limits of acceptable change are set just outside the margins of the range of condition as recorded from history. The dashed lines illustrate that longer cycles of change may challenge even this record of natural variability. More realistically, there is little continuous monitoring data that extends far beyond the time of listing to realistically assess variation in any parameter, and so paleoecological records are essential in defining limits. 


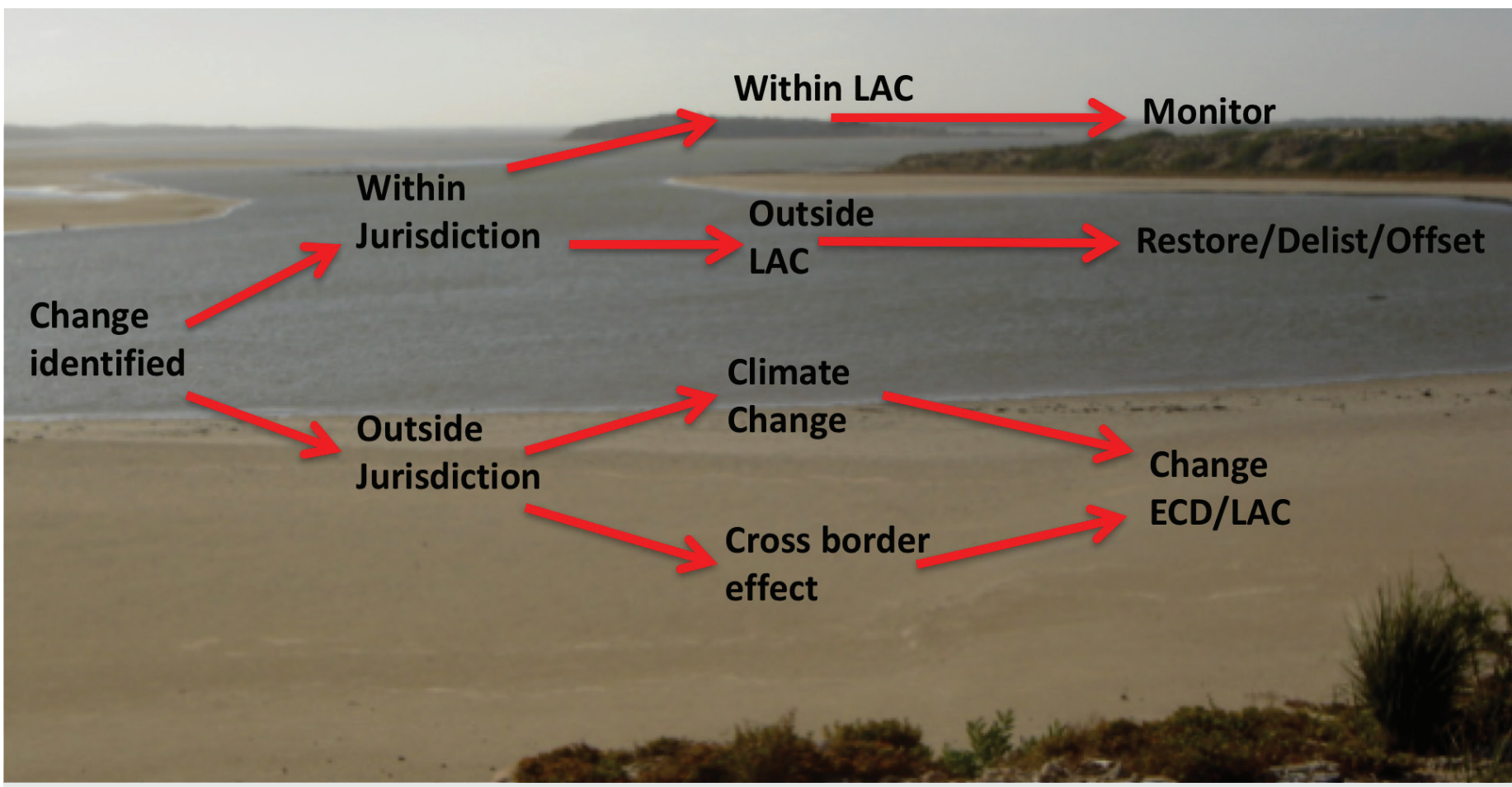

Figure 2: Proposed pathway to guide action following the identification of change to a Ramsar listed wetland. Paleoecological approaches can assist in assessing if the driver of change is within or outside the jurisdiction of the signatory party, whether it is within or outside limits of acceptable change (LAC) and whether it is in response to global climate change or a cross border effect. Nations are required to restore or offset when the change is outside long-term variability and if the driver of change is the responsibility of the signatory nation. ECD: Ecological character descriptions. Photo: The Coorong Ramsar site, Australia; Peter Gell.

\section{Paleoecology and Ramsar wetlands}

There have been many records of paleoecological research on Ramsar wetlands, although it is possible that not all researchers were aware of the status of the site at the time of listing, relative to its historical past. Evidence from the Coorong, Lower Lakes and Murray Mouth site in Australia revealed that the site description at the time of listing in 1985 reflected a condition that had changed in the 1950s (Reeves et al. 2015) and was unrepresentative of what would be considered the natural long-term baseline (Gell 2017). Ramsar sites along the Nile Delta have also been shown to have been substantially impacted in recent decades and that the present condition is a departure from the long-term baseline (Flower et al. 2001).

Paleoecological research can also provide direct evidence on the status and breeding success of significant waterbird populations. Loch Ruthven near Inverness in Scotland was listed as a Ramsar site in 1996 mainly by way of the important population of breeding Slavonian Grebe it hosts. Brooks et al. (2012) used a sediment record to relate the annual recruitment success of Slavonian Grebe, based on historical surveys, to the availability of chironomid prey for the hatchlings, as recorded in the lake sediments. The increased nutrient load is linked to larger populations of this key food item for the Grebe chicks leading to enhanced recruitment and securing one of the main criteria of the loch's listing.

PAGES has a long history of documenting the impact of people and climate on wetlands through themes, projects and working groups e.g. LIMPACS and Aquatic Transitions. Many records attest to considerable condition change both before and since the Convention began. So, from a paleoecological perspective, it is clear that long-term records have the capacity to provide better understanding of present condition in the context of variability, including the impacts of low-frequency climate cycles, as well as providing records of shifting baselines due to human impact. Acknowledging this, PAGES and the Ramsar Secretariat hosted a workshop in Queenscliff, Australia, in late 2013 to examine the opportunities that may exist, for the Convention and for paleoecological researchers, to bring a long-term perspective to the identification of character and the setting of acceptable limits to change based on knowledge of long-term variability. The proceedings of this workshop are published in a special issue of Marine and Freshwater Research (Gell and Finlayson 2016), including an editorial from the previous Ramsar Convention Secretary General (Davidson 2016) declaring the benefits that paleoecology can bring to more realistic assessments of the world's wetlands of international significance.

\section{Shifting baselines and limits of acceptable change}

While it remains challenging for nations to identify how current wetland conditions have deviated from long-term trends, if only a recent state is used as a baseline the failure to consider pre-listing state allows for all of the previous human impact to be excused, potentially perpetuating mismanagement in a degraded state (Finlayson et al. 2016). The Millennium Ecosystem Assessment documented widespread reduction in the extent and condition of freshwater wetlands worldwide, so it is implicit that time-of-listing condition is unlikely to reflect the range of wetland conditions before impact by industrialized society. Without long-term data, nations might continue to manage for a derived, and perhaps less productive, wetland than previously existed.

Conversely, armed with a better understanding of variability and defined limits of acceptable change, a nation is better equipped to decide when and how to act, and when to report change as being outside, or within, past historical range. Further, it is unreasonable if a nation is held to account for the change in the state of a wetland if the driver of that change is due to the actions of a neighbor (e.g. upstream), or is global (e.g. climate change) in scale. By partitioning human impact from climate, and proximal and distal causes of change, paleoecology can assist with an appropriate pathway for the Ramsar Secretariat to assess the obligation of nations to act (Fig 2).

\section{AFFILIATIONS}

Water Research Network, Federation University Australia, Ballarat, Australia

\section{CONTACT}

Peter A. Gell: p.gell@federation.edu.au REFERENCES

Brooks SJ et al. (2012) J Paleolimn 47(4): 631-644

Davidson NC (2016) Mar Fresh Res 67: 685-686

Dudgeon D et al. (2006) Biol Rev 81: 163-182

Finlayson CM et al. (2016) Mar Fresh Res 67: 687-694 Flower RJ et al. (2001) Aq Ecol 35: 369-388 Gell PA, Finlayson CM (2016) Mar Fresh Res 67(6)

Gell PA (2017) In Weckström K et al. (Eds) Applications of Paleoenvironmental Techniques in Estuarine Studies. Developments in Paleoenvironmental

Research, Springer, 615-662

\section{Junk WJ et al. (2013) Aq Sci 75: 151-167}

Phillips B (2006) Critique of the Framework for describing the ecological character of Ramsar Wetlands.

Mainstream Environmental Consulting Pty Ltd

Reeves JM et al. (2015) Estuar Coasts 38: 2101-2116 